\title{
A Contrastive Study on Generic Structure of Introduction to English Chemistry Research Articles: L1 Chinese Student Writers versus L1 English Published Writers
}

\author{
Zhigang $\mathrm{Yu}^{1} \&$ Min Liu ${ }^{1}$ \\ ${ }^{1}$ School of Foreign Languages, Jiangsu University, Zhenjiang, China \\ Correspondence: Zhigang Yu, School of Foreign Languages, Jiangsu University, Zhenjiang, \#301 Xuefu Road, \\ Jingkou District, Jiangsu, China. E-mail: 609628816@qq.com
}

Received: June 17, 2016 Accepted: July 11, 2016 Online Published: September 23, 2016

doi:10.5539/ijel.v6n5p112 URL: http://dx.doi.org/10.5539/ijel.v6n5p112

\begin{abstract}
Introduction is a significant part-genre of a research article (RA) since it functions to persuade the readership that their research topic has some significance, that there is space for new knowledge around the topic and that the writer can make a contribution to knowledge. Previous studies mainly focused on experienced English L1 and L2 published writers. Masters majoring in Chemical Engineering in China are highly motivated to publish English RAs in international journals due to the requirements for graduation, but to date no work investigates into the disparity between their English RA introductions (ERAIs) and that of high impact SCI journals in terms of generic structure. To fill this gap, drawing on Swales' CARS model $(1990,2004)$, this study analyzed the ERAIs written by L1 Chinese masters majoring in chemical engineering and L1 English published writers of the same discipline with a focus on the generic structure. The findings show that the NES published writers employ much more moves than the Chinese student writers, especially Move 1 "establishing a territory" and Move 2 "establishing a niche". Due to the lack of Move 2, the completeness of the general organization of ERAIs written by the Chinese student writers is much weaker than the NES published writers. From the perspective of the constituent steps, the findings show that the lack of Move 1-Step 3 causes the overall insufficiency of Move 1 in the student writer group (SWG) compared with the published writer group (PWG) and the inadequate Step 1A "indicating a gap" leads to the overall deficiency of Move 2 in SWG. In Move 3, Step 1 is most frequently used in both groups. Although Step 5 and Step 6 are employed in this move but their frequency is low and quite similar to each other in these two groups. The findings have some pedagogical implication on the teaching of writing ERAIs.
\end{abstract}

Keywords: introductions to English Chemistry Research Articles, CARS model, L1 Chinese student writers, L1 English published writers

\section{Introduction}

With the exchange between different scholars in the international scientific academia becoming increasingly frequent, English RAs have become a major channel for distributing academic ideas and advancing scientific knowledge among members of the international scientific research communities. Conventionally, the body of a RA consists of four parts: Introduction, Methods, Results and Discussion (Swales, 1990; Hyland, 1998). Among them, Introduction is a significant "part-genre" (Dudley-Evans, 2000) since it achieves the key communicative purpose of "creating a research space in a particular research field" (Swales, 1990, p. 142). ERAIs play an important role in "capturing the interest of readers, especially the international peer reviewers, and convincing them of the work's novelty" (Lim, 2012, p. 229), and hence influence the acceptability of the article by international journals. Therefore, for researchers, especially the non-native English speaking (NNES) researchers highly motivated to publish articles in international journals, it is indispensable to master this particular part-genre in terms of its generic structure which are acceptable to the international discourse community where the researchers belong.

Since the proposal of the seminal Create a Research Space (CARS) Model for RA introductions by Swales in 1990, research article introductions have received special attention from researchers as well as teachers focusing on English academic writing. Scholars have applied the CARS model to ERAIs for various purposes: (1) 
identifying the generic structure of a specific discipline including software engineering (Anthony, 1999), biochemistry (Kanoksilapatham, 2005), forestry (Joseph et al., 2014) and mathematics (Graves, 2014); (2) analyzing the difference in generic structure between different disciplines (Samraj, 2002) and between different sub-disciplines of one same discipline including two sub-disciplines of applied linguistics (Oztruk, 2007) and three sub-disciplines of engineering (Kannoksilapatham, 2015); (3) contrasting the generic structure of a specific discipline written by NNES writers and native English speaking (NES) writers including Spanish L1 writers and English L1 writers (Sheldon, 2011), and Chinese L1 writers and English L1 writers (Taylor \& Chen, 1991; Hu, 2005). It can be summarized that previous studies mainly focus on disciplinary and cultural influence on the generic structure of ERAIs. However, as a primary discipline which is fundamental to many other scientific disciplines such as material engineering and biology, chemistry discipline has not received as much attention as it deserves from previous studies. On the other hand, the previously studied L1 Chinese student writers are only limited to masters majoring in English linguistics. To date, chemical students in Mainland China have not been studied yet though they are "highly motivated to publish English RAs in international journal due to the requirements for graduation" (Li \& Flowerdew, 2007). To fill the gaps mentioned above, the present study, pedagogically motivated, purports to comparatively analyze the ERAIs written by L1 Chinese masters majoring in Chemical Engineering and L1 English published writers of the same discipline with a focus on the generic structure. The specific research questions addressed in this study are: (1) what are the similarities and difference between the two sets of introductions in terms of the general moves? (2) what are the similarities and differences between the two sets of introductions in terms of the constituent steps?

\section{Methods}

\subsection{Corpus}

The corpus for the present study consists of 40 ERAIs - 20 written by L1 Chinese student writers and 20 by English published writers - of chemical engineering disciplines. ERAIs in the SWG are extracted from the first drafts of the English RAs written by some first-year Chinese master students majoring in Chemical Engineering from Jiangsu University. ERAIs in the PWG are obtained from RAs published in a SCI journal named Journal of Solid State Chemistry with a high impact factor (average in the past three years: 4.561). The identification of NES writers is strictly in conformity with Wood's (2001, pp. 78-79) criteria of identifying NES writers in Science and Nature: "an author whose whole name appear to be English convention and affiliation locates in English speaking country is recognized as a NES writer". Since different disciplines and sub-disciplines have their own variations attested in past studies (Samraj, 2002; Anthony, 1999; Ozturk, 2007), the topics of the two groups are correspondent with each other and all belong to the one same sub-discipline - material processing and synthesis. All the RAs from which the introductions are extracted are experimental articles and their generic structure is in line with the standard IMRD structure.

\subsection{Analysis Framework}

Swales proposed the ground-breaking analytical model — CARS model—in 1990 and revised it in 2004. The two models are listed in table 1:

Table 1. The two CARS models

\begin{tabular}{ll}
\hline Swales' CARS model (1990) & Swales' CARS model (2004) \\
\hline Move 1: Establishing a territory & Move 1: Establishing a territory (Citation required) \\
Step 1: Claiming centrality, and/or & Step 1: Topic generalizations of increasing specificity \\
Step 2: Making topic generalization, and/or & \\
Step 3: Reviewing previous items of research & \\
\hline Move 2: Establishing a niche & Move 2: Establishing a niche \\
Step 1A: Counter-claiming or & Step 1A: Indicating a gap or \\
Step 1B: Indicating a gap or & Step 1B: Adding to what is known) \\
Step 1C: Question-raising or & Step 2: (optional) Presenting positive justification \\
Step 1D: Continuing a tradition & \\
\hline Move 3: Occupying the niche & Move 3: Presenting the present work \\
Step 1A: Outlining purposes or & Step 1: (Obligatory) Announcing present research descriptively and/or purposively \\
Step 1B: Announcing present research & Step 2: (optional) Presenting research questions or hypotheses \\
Step 2: Announcing principal findings & Step 3: (optional) Definitional clarifications \\
Step 3: Indicating RA structure & Step 4: (optional) Summarizing methods (Note 1) \\
& Step 5: (PISF)Announcing principal outcomes(Note 2) \\
& Step 6: (PISF) Stating the value of the present research \\
& Step 7: (PISF) Indicating the structure of the paper \\
\hline
\end{tabular}


Compared with Move 1 in the 1990 CARS model (hereafter the original model), the 2004 CARS model (hereafter the revised model) reduces the three steps to one since Swales claims (2004) that sometimes it is difficult to operationalize the distinction between Move 1-Step 1 "claiming centrality" and Move 1-Step 2 "making topic generalizations" and the Step "topic generalizations of increasing specificity" can better account for the overall structure of move 1. However, this revision seems to have not withstood the test of later investigations and critical commentary. Some scholars point out that the revised Move 1 is "too broad" (Sheldon, 201, p. 240), therefore it may "miss interesting strategies employed by the authors" (Adnan, 2008, p. 48) and "hinder the identification of the linguistic strategies enacted by writers for the realization of such moves" (Rubio, 2011). Besides, Kannoksilapatham (2015) studied the textual organization of 180 ERAIs of engineering disciplines according to the textual analysis units called "move" and "step" and finds that the rhetorical structure is exactly the same to that of Swales' model. These recent studies prove that the original Move 1 can provide a more useful account of the rhetorical structure. Hence, the analysis framework of ERAIs' generic structure adopts Move 1 of the 1990 CARS model.

Move 2 of the two models is labelled the same name but constituted by different steps. Swales replaced Step 1D "continuing a tradition" with Step 1B "adding to what is known" for that "“continuing a tradition' seems a rather odd choice of nomenclature" (Swales, 2004, p. 229). In addition, Step 1A "counter-claiming" and Step 1C "question-raising" "may not functionally be very different from gap-indication" (Swales, 2004, p. 230). Thus, Swales reduces these two steps to "indicate a gap". Considering the deviation reported in Samraj's study that "in five of twelve wildlife behavior introductions a gap indication was immediately followed by a step named "presenting positive justification"' (Samraj, 2002, p. 15), Swales added this step into the revised Move 2 as an optional step. The revision successfully accounts for the limitation in the original Move 2 and the revised Move 2 appears justifiable. Therefore, the analysis framework of ERAIs' generic structure follows Move 2 of the 2004 CARS model.

Move 3 in the original model is named "occupying the nice" while "presenting the present work" in the revised model. Though labeled different names, the role of Move 3 in the two models is the same - to justify the present article by occupying the research space. Step 1A "outlining purposes" in Move 3 of the original model is to "indicate the study's main purpose or purposes" (Swales, 1990, p. 159), and Step 1B "announcing present research" is to "describe what the authors consider to be the main features of their research" (Swales, 1990, p. 159). However, a recurring problem is that it is not easy to separate these two steps sometimes. Take the following paragraph as an example: "the purposes of this paper are the following a) to classify verbal report data into two types...and to describe...b) to summarize...c) to methodologically review introspective studies...and d) to discuss..." A coder would fall into dilemma whether to code it as Step 1A or Step 1B as this group of sentences can not only state the purpose of the study but also tell the structure of the study. Therefore, Swales replaced the opening step in Move 3 of the original model with the step "announcing present research descriptively and/or purposively". Compared with Move 1 of the original model, three optional steps ("presenting research questions or hypotheses", "definitional clarifications" and "summarizing method") are added and situated after Step 1. In Anthony's study (1999), the step "announcing principle findings" is followed by a step what he calls evaluation of research in all the studied 12 RAs. Swales added in the revised Move 3 this step but only probable in some fields. Since the final step in Move 3 is related to whether the article is in IMRD sectional arrangement, Swales revised "indicating the structure of the paper" as probable in some fields. The revised Move 3 is quite elaborated and complete than the original one. Therefore, the analysis framework of ERAIs' generic structure adopts Move 3 of the revised model.

In summary, the moves and steps that I have used to analyze the rhetorical structure of ERAIs are summarized as below: 
Table 2. The present analysis framework of the generic structure of ERAIs

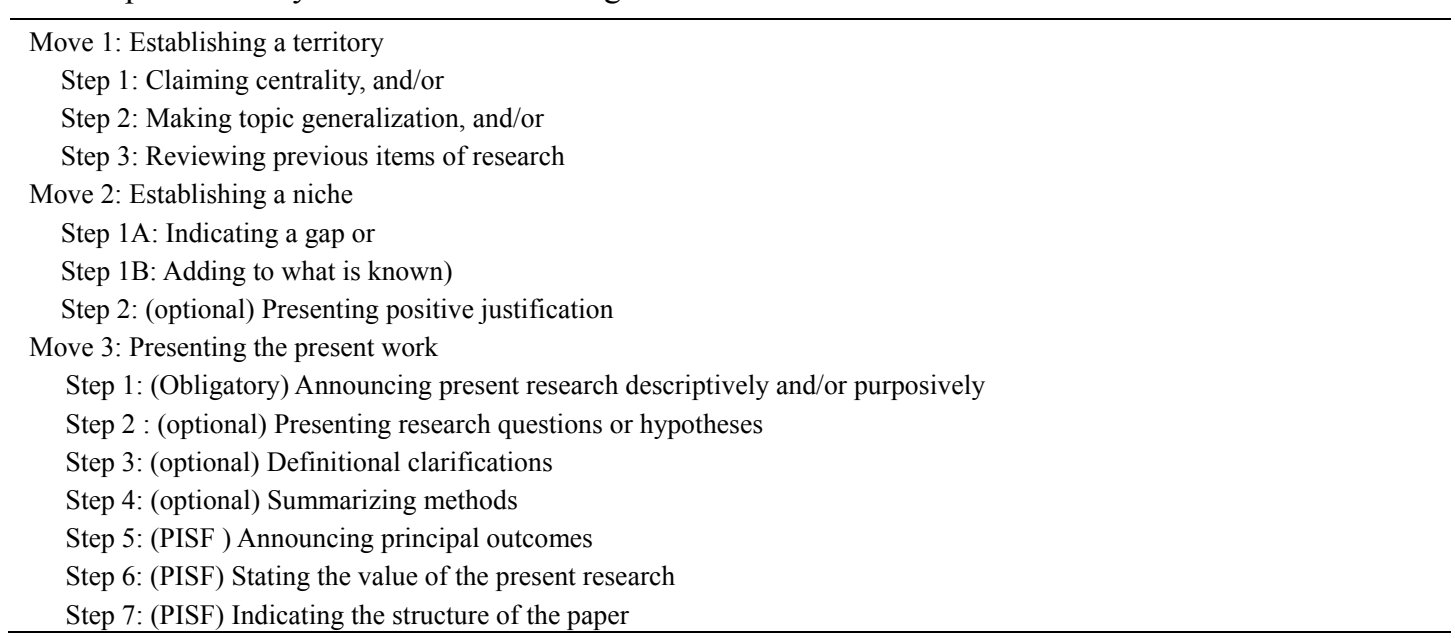

\subsection{Coding and Reliability of Move Identification}

The coding rule for this study is the analysis framework listed above. Since move identification is based on the coders' intuitive understanding of the communicative function of a group of sentences, the identification has been criticized of being "purely subjective" (Crook, 1986, p. 107) and "the consistency in analysis can be difficult to arrive at" (Hood, 2010, p. 10). Hence, the reliability of move identification by a single coder can be low. However, Crook (1986) argues that the reliability can be believed to be high if a group of trained coders reach an adequate level of agreement. To insure a strong validity and high reliability of move identification, this study followed Crook's method (1986, pp. 107-108). We invited another master majoring in applied linguistics (TEM 8: merit) (Note 3) to complete the identification. The invited coder was trained to become acquainted with the coding rules so as to ensure that she clearly understood how to code the text. After the training, the two coders practiced analyzing five ERAIs and checked through the coding disagreements to achieve a common and correct understanding of the coding rules. Finally, the coders finished the coding independently. The inter-coder reliability was tested by Cohen's (1960) measurement of coefficient of agreement for nominal scales. The result is listed in table 3 . The Cohen $k$ (Note 4 ) is 0.82 suggesting that the inter-coder reliability is excellent.

Table 3. Results of inter-coder reliability test

\begin{tabular}{lllll}
\hline Move & Coded units & Agreement & Disagreement & Cohen $k$ \\
\hline Move 1 & 420 & 382 & 38 & \\
Move 2 & 88 & 76 & 12 & \\
Move 3 & 249 & 212 & 37 & 0.82 \\
Total & 757 & 670 & 87 & \\
\hline
\end{tabular}

\subsection{Data Analysis}

After the coding was finished, the data was collected and saved in Excel tables for comparative analysis. SPSS 17.0 was used to analyze the two groups of data when necessary.

\section{Results}

\subsection{Comparison of Moves in the Two Sets of Introductions}

Table 4. The frequency of occurrence of moves in the two sets of introductions

\begin{tabular}{lllll}
\hline & \multicolumn{2}{l}{ Student writer group } & \multicolumn{3}{l}{ Published writer group } \\
& Number & Frequency $(\mathrm{N}=20)$ & Number & Frequency $(\mathrm{N}=20)$ \\
\hline Move 1 & 23 & 1.15 & 48 & 2.4 \\
Move 2 & 14 & 0.7 & 28 & 1.4 \\
Move 3 & 20 & 1 & 32 & 1.6 \\
\hline
\end{tabular}


Table 4 indicates that the frequency of occurrence of Move 1 and Move 2 in the PWG is roughly two times the SWG and Move 31.6 times. Statistics of move recycling shows that two-move cycle pattern (M1-M2) occurs 3 times in the SWG and 13 times in the PWG, and three-move cycling pattern (M1-M2-M3) occurs 5 times in the PWG but none in the SWG.

\subsection{Comparison of the Constituent Steps of Each Move in the Two Sets of Introductions}

To further understand the occurrences and distribution of the constituent steps, this study collected data of the specific steps. The result is listed in table 5 .

Table 5. Frequency of occurrences and distribution of the constituent steps

\begin{tabular}{|c|c|c|c|c|c|}
\hline \multirow[b]{2}{*}{ Steps } & & \multicolumn{2}{|c|}{ Student writer group } & \multicolumn{2}{|c|}{ Published writer group } \\
\hline & & Number & $\begin{array}{l}\text { Frequency } \\
(\mathrm{N}=20)\end{array}$ & Number & Frequency $(\mathrm{N}=20)$ \\
\hline \multirow{3}{*}{ Move 1} & Step 1 & 22 & 1.1 & 23 & 1.5 \\
\hline & Step 2 & 34 & 1.7 & 38 & 1.9 \\
\hline & Step 3 & 20 & 1 & 62 & 3.1 \\
\hline \multirow{3}{*}{ Move 2} & Step 1A & 14 & 0.7 & 24 & 1.2 \\
\hline & Step 1B & 0 & 0 & 3 & 0.15 \\
\hline & Step 2 & 6 & 0.3 & 5 & 0.25 \\
\hline \multirow{7}{*}{ Move 3} & Step 1 & 20 & 1 & 30 & 1.5 \\
\hline & Step 2 & 0 & 0 & 0 & 0 \\
\hline & Step 3 & 0 & 0 & 0 & 0 \\
\hline & Step 4 & 0 & 0 & 2 & 0.1 \\
\hline & Step 5 & 3 & 0.15 & 6 & 0.3 \\
\hline & Step 6 & 6 & 0.3 & 9 & 0.45 \\
\hline & Step 7 & 0 & 0 & 0 & 0 \\
\hline
\end{tabular}

In Move 1, the results show that the frequency of occurrence of step 1 and step 2 are very close in the two sets of introductions while the frequency of occurrence of step 3 in PWG is much higher than that in SWG. In Move 2, Step $1 \mathrm{~A}$ is the most frequently used step by both groups but the frequency of its occurrence in the PWG is nearly 2 times the SWG. In Move 3, Step 1 is predominant in both groups with the SWG slightly more than the PWG in terms of its frequency of occurrence. Step 5 and Step 6 are also used in the two groups but the frequencies in both groups are rather low.

\section{Discussion}

The results in table 4 shows that the moves employed by the student writers are much less than the NES published writers, Move 1 and Move 2 in particular. It is also worth noting that the number of Move 2 in the SWG is less than the total number of ERAIs. Statistics of move pattern indicates that about $42 \%$ of the ERAIs in the SWG follow M1-M3 pattern, which suggests that the general organization of some of the ERAIs in the SWG is not complete compared with the PWG. This finding is different from Taylor \& Chen's study (1991) on ERAIs written by Chinese published writers and American published writers. They find that the generic structure of the ERAIs written by the Chinese published writers generally conforms to the CARS model. Since the student writers in this study and the Chinese published writer in Taylor \& Chen's study are both Chinese, the cultural influence on generic structure is excluded. The reason attributing to the difference in the completeness of generic structure may lie in that the student writers are not as acquainted as the published writers with the textual regularities and communicative purposes of different moves of ERAIs. In other words, the student writer's genre awareness of ERAIs is lower than that of the published writers. Not aware of the key communicative purpose of ERAIs, that is, establishing a research space, the student writers inevitably fail to include Move 2 " establishing a niche" in the ERAIs. This finding well correlates with the current English academic writing courses provided by the researched university. Although the student writers have taken 36 hours of English academic writing course in the first grade, no specific effort of the class has been devoted to raising the genre awareness of ERAIs. Many studies have shown that explicit instruction of generic features in genre-based pedagogies (Hyon, 2001; Swales \& Lindermann, 2002; Huang, 2014) can improve students' genre awareness and "facilitate the transference of genre knowledge learned in the classroom to authentic writing task" (Huang, 2014, p. 176). Therefore, we advocate that explicit genre-based pedagogy should be implemented to raise students' genre awareness of ERAIs in English academic writing courses in universities in China. 
Table 4 suggests that Move 1 in the SWG is far less than that in the PWG, while table 5 shows that there is no distinct difference in Move 1-Step 1 and Move 1-Step 2 between the two groups but marked difference in Move 1-Step 3. Thus, it can be concluded that the inadequate Move 1-Step 3 causes the overall insufficiency of Move 1 in the SWG compared with the PWG. The finding that Move 1-Step 3 "reviewing previous items of research" is deficient in the EARIs written by Chinese student writers while predominant in EARIs written by NES published writers is consistent with Hu's study (2005) on ERAIs selected from Chinese English scientific journals. Hu (2005) argue that "Chinese scholars are reluctant to discuss the work of colleagues for fear of rendering that work subject to exposure in subsequent description of the gaps between established and new territory". Move 1-Step 3 "reviewing previous items of research" functions to report previous studies with a stance towards the findings (Swales, 1990, p. 148), which lays ground for Move 2-Step 1A "indicating a gap" detailing gaps in the extant literature. Due to the significance of face saving in Chinese culture, Chinese writers find it inappropriate to review the previous studies which may be exposed to the critical evaluation by Move 2. This cultural influence then probably explains why student writers in this study are deficient in the step "reviewing previous items of research".

As shown in table 5, both groups mainly use "indicating a gap" as the constituent step of Move 2 but the frequency of occurrences in the SWG is much lower than that in the PWG. It proves that the lack of Step 1A "indicating a gap" leads to the overall deficiency of Move 2 in SWG. The finding that the occurrence of Move 2-Step 1A "indicating a gap" in the SWG is much less than that of the PWG is in line with previous studies (Taylor \& Chen, 1991; Chek, 2010). Taylor \& Chen's study on ERAIs written by NNES Chinese published writers shows that experienced though these writers are, they still avoid highlighting shortcomings of previous studies and thus omit the step "indicating a gap". In addition to the face-saving culture in Chinese society that may be accountable for this finding, the Confucian principle of constant mean (zhong yong) is another important socio-cultural factor accountable for the Chinese writers' avoidance of employing the step "indicating a gap". The principle "guides people not to be extreme but to adopt the middle way" (Wang, 2007, p. 11). Therefore, criticizing others' work is taken as unacceptably antagonistic by Chinese writers. To avoid being extreme in writing ERAIs, the Chinese student writers may choose to omit the step "indicating a gap". Besides, the Chinese traditional ideology that "people with lower social status should respect those with higher one and be cautious with their words and acts" (Sun, 2010, p. 59) can be another socio-cultural factor influencing the student writers' employment of the step "indicate a gap". With the identity of students, the Chinese masters majoring in engineering disciplines may "respect the experienced scholars' claim and not dare to challenge them" (Xu, 2007, p. 50). As a result, the student writers are inclined to omit the step "indicating a claim". Based on the above analysis, it can be concluded that socio-cultural factors shape the rhetorical organization of ERAIs written by the Chinese masters in an important way. Therefore, it is pressing that the Chinese student writers should mitigate the negative influence posed by the home culture on writing ERAIs and take up the conventions and values accepted by the target discourse community. Devitt $(2009$, p. 343) also points out that "research articles are value-laden and ideology-laden genre. To master this genre, one needs to master the values carried by the genre." We suggest that English academic writing courses should adopt the ESP genre pedagogy approach which "aims to help students build their membership in their discourse community by guiding them to construe the interaction between genre and the discourse community, to understand how language functions in the context of communication and what is expected of them to successfully participate in the context, and ultimately, to master the valued genres that will add to their cultural capital" (Huang, 2014, p. 176). When the values carried by ERAIs is added to Chinese student writers' cultural capital, the barriers blocking them from becoming members of the target discourse community will be cleared.

Table 5 shows that Step 1 is predominant in Move 3 in both groups and the disparity of Move 3 between the two groups is close to the disparity of Step 1A. Although Step 5 and Step 6 are also employed by both groups, their frequency is low and quite close to each other. The finding that the occurrence of Step 1 in Move 3 in the SWG than that in the PWG can probably be explained by the student writers' failure to establish niche in Move 2 . Swales (1990, p. 159) points out that "the role of Move 3 is to turn the niche established in Move 2 into the research space that justifies the present article". As attested above, Move 2 in the SWG is much less than that the PWG, which means less niche will be occupied by the work. This then explains why Step 1 in Move 3 in the SWG is less than that in the PWG.

\section{Conclusion}

This study analyzed the similarities and differences of generic structure between the English chemistry RAs written by Chinese masters majoring in Chemical Engineering and NES published writers from the same discipline. The findings show that the NES published writers employ much more moves than the Chinese student 
writers, especially Move 1 and Move 2. Due to the lack of Move 2, the completeness of the general organization of ERAIs written by the Chinese student writers is much weaker than the NES published writers. From the perspective of the constituent steps, the findings show that the lack of Move 1-Step 3 causes the overall insufficiency of Move 1 in the SWG compared with the PWG and the inadequate Step 1A "indicating a gap" leads to the overall deficiency of Move 2 in SWG. In Move 3, Step 1 is most frequently used in both groups. Although Step 5 and Step 6 are employed in this move but their frequency is low and quite similar to each other in these two groups.

Different from previous studies taking use of questionnaires, interviews and inductive data to research Chinese students' ability of English academic writing, this study collected data from the actual academic works of masters of Chemical Engineering and hence is able to reveal problems that are difficult for students to realize subjectively, let alone questionnaires and interviews. Therefore, the findings of this study help students find the shortages in writing ERAIs, which can provide some insight to the improvement of English academic writing courses provided by universities in China. We propose that English academic writing courses should substantially implement the genre-based teaching approach since it effectively helps students acquire the communicative purposes of a target genre and its textual regularities which improve their awareness of the genre and hence conquer the negative influence from home culture on preventing them becoming members of target discourse community (Kay \& Dudley-Evans, 1998, p. 31). Genre-based pedagogical approach on ERAIs, especially the explicit instruction, can assist students to get acquainted with the communicative purposes of each move as well as move cycling patterns, particularly the cycling between Move 1 and Move 2.

\section{Acknowledgement}

This study was financially supported by the 2015 Innovative Planned Research Project for Postgraduates in Universities in Jiangsu Province (KYZZ15_0288).

\section{References}

Anthony, L. (1999). Writing research article introductions in software engineering: How accurate is the standard model? IEEE Transactions of Professional Communication, 2, 38-46. http://dx.doi.org/10.1109/47.749366

Chek, K. L., \& Moyra, S. E. (2010). Cultural differences in the organization of research article introductions from the field of educational psychology: english and chinese. Journal of Pragmatics, 10, 2814-2825. http://dx.doi:10.1016/j.pragma.2010.03.010

Cohen, J. (1960). A coefficient of agreement for nominal scales. Educational and Psychological Measurement, 1, 37-46. http://dx.doi.org/10.1177/001316446002000104

Crookes, G. (1986). Towards a validated analysis of scientific text structure. Applied Linguistics, 1, 57-70. http://dx.doi.org/10.1093/applin/7.1.57

Devitt, A. J. (2009). Teaching critical genre awareness. In C. Bazerman, A. Bonini, \& D. Figueredo (Eds.), Genre in a Changing World (pp. 342-355). CO: The WAC Clearinghouse and Parlor Press.

Dudley-Evans, T. (2000). Genre analysis: A key to a theory of ESP? Iberica, 2, 3-11.

Grave, H. (2014). "Let $\mathrm{G}=(\mathrm{V}, \mathrm{E})$ be a graph": Turning the abstract into the tangible in introductions in mathematics research articles. Journal of English for Specific Purposes, 3, 1-11. http://dx.doi.org/10.1016/j.esp.2014.03.004

Hood, S. (2010). Appraising Research: Evaluation in Academic Writing. NY: Palgrave Macmillan. http://dx.doi.org/10.1057/9780230274662

$\mathrm{Hu}, \mathrm{R}$. (2005). A Contrastive Study on the Introductions to Chinese and Foreign English Journal Articles. Hua Zhong University of Science and Technology.

Huang, J. C. (2014). Learning to write for publication in English through genre-based pedagogy: A case in Taiwan. System, 5, 175-186. http://dx.doi.org/10.1016/j.system.2014.05.010

Hyon, S. (2001). Long-term effects of genre-based instruction: a follow-up study of an EAP reading courses. Journal of English for Specific Purposes, 20, 417-438. http://dx.doi.org/10.1016/S0889-4906(01)00019-9

Joseph, R., Lim, J. M., \& Nor, N. A. M. (2014). Communicative moves in Forestry research introductions: Implications for the design of learning materials. Procedia, 4, 53-69. http://dx.doi:10.1016/j.sbspro.2014.04.224

Kannoksilapatham, B. (2015). Distinguishing textual features characterizing structural variation in research articles across three engineering sub-discipline corpora. English for Specific Purposes, 6, 74-86. 
http://dx.doi.org/10.1016/j.esp.2014.06.008

Kanoksilapatham, B. (2005). Rhetorical structure of biochemistry research articles. English for Specific Purposes, 3, 269-292. http://dx.doi:10.1016/j.esp.2004.08.003

Kay, H., \& Dudley-Evans, T. (1998). Genre: What teachers think. ELT Journal, 4, 308-314. http://dx.doi.org/10.1093/elt/52.4.308

Li, Y., \& Flowerdew, J. (2007). Shaping Chinese novice scientists' manuscripts for publication. Journal of Second Language Writing, 2, 101. http://dx.doi.org/10.1016/j.jslw.2007.05.001

Lim J. M. (2012). How do writers establish research niches? A genre-based investigationinto management researchers' rhetorical steps and linguistic mechanisms. Journal of English for Academic Purposes, 11, 229-245. http://dx.doi:10.1016/j.jeap.2012.05.002

Rubio, M. M. S. (2011). A pragmatic approach to the macro-structure and metadiscoursalfeatures of research article introductions in the fieldof Agricultural Sciences. English for Specific Purposes, 3, 258-271. http://dx.doi:10.1016/j.esp.2011.03.002

Samraj, B. (2002). Introductions in research articles: Variations across disciplines. Journal of English for Specific Purposes, 8, 1-18. http://dx.doi.org/10.1016/S0889-4906(00)00023-5

Sheldon, E. (2011). Rhetorical differences in ra introductions written by english 11 and 12 and castilian spanish 11 writers. Journal of English for Academic Purposes, 4, 238-251. http:// dx.doi:10.1016/j.jeap.2011.08.004

Sun, X. H. (2010). Analyzing the generic structure of introductions to graduation thesis written by Chinese masters majoring in English linguistics. Foreign languages in China, 6, 59-60.

Swales, J. M. (1990).Genre Analysis: English in academic settings. Cambridge: Cambridge University Press.

Swales, J. M. (2004). Research genres: Exploration and applications. Cambridge: Cambridge University Press. http://dx.doi.org/10.1017/CBO9781139524827

Swales, J. M., \& Lindemann, S. (2002). Teaching the literature review to international graduate students. In M. J. Ann (Ed.), Genre in the classroom (pp.105-119). NY: Routledge.

Taylor, G., \& T. Chen. (1991). Linguistic, cultural, and sub-cultural issues in contrastive discourse analysis: Anglo-American and Chinese scientific texts. Applied Linguistics, 12, 319-336. http://dx.doi.org/10.1093/applin/12.3.319

Wang, W. H. (2015). Claiming centrality as promotion in applied linguistics research article introductions. Journal of English for Academic Purposes, 5, 162-175. http://dx.doi.org/10.1016/j.jeap.2015.05.002

Wood, A. (2001) International scientific English: The language of research scientists around the world. In J. Flowerdew \& M. Peacock (Eds.), Research Perspectives on English for Academic Purposes (pp. 71-83). Cambridge: Cambridge University Press. http://dx.doi.org/10.1017/CBO9781139524766.008

Xu, Y. Z., Guo, Y. Z., \& Xu, T. (2007). The indispensable genre-based academic writing teaching-an investigation on introduction to graduation thesis written by masters majoring in English linguistics. Foreign languages in China, 4, 47-51.

\section{Notes}

Note 1. Step 2-4 are not only optional but less fixed in their order of occurrence than the others.

Note 2. PISF: Probable in some fields, but unlikely in others.

Note 3. TEM 8 is the abbreviation of test for English major band 8. It is the highest English language proficiency test for English majors in Mainland China.

Note 4. The formulation of computing Cohen $\mathrm{k}$ is $\mathrm{k}=\frac{p_{0}-p_{c}}{1-p_{c}}$. $\mathrm{p}_{\mathrm{o}}$ is the proportion of units in which the coders agreed. $p_{c}$ is the proportion of units for which agreement is expected by chance. The coefficient $k$ is the proportion of agreement after chance agreement is removed from consideration (Cohen, 1960, p. 40). The interpretation of Cohen $\mathrm{k}$ is: less than 0.40 means poor, $0.40-0.59$ fair, $0.60-0.74$ good, and more than 0.75 excellent. 


\section{Copyrights}

Copyright for this article is retained by the author(s), with first publication rights granted to the journal.

This is an open-access article distributed under the terms and conditions of the Creative Commons Attribution license (http://creativecommons.org/licenses/by/4.0/). 